\title{
Hepatitis B and C Infections in Patients With Prolonged Hemodialysis Secondary to Chronic Renal Failure
}

\author{
Wajeeha Elahi ${ }^{1}$, Ameen Zubair Syed ${ }^{1}$, Fahad Nasim ${ }^{2}$, Adnan Anwar ${ }^{3,4}$, Atif A. Hashmi ${ }^{5}$ \\ 1. Nephrology, Tabba Kidney Institute, Karachi, PAK 2. Nephrology, Liaquat National Hospital and Medical College, \\ Karachi, PAK 3. Physiology, Al-Tibri Medical College, Karachi, PAK 4. Stereotactic Radiosurgery/Radiation Oncology, \\ Al-Tibri Medical College, Karachi, PAK 5. Pathology, Liaquat National Hospital and Medical College, Karachi, PAK
}

Corresponding author: Atif A. Hashmi, atifhashmi345@gmail.com

\section{Abstract}

\section{Objective}

To determine the frequency of hepatitis B and C in patients with prolonged hemodialysis suffering from chronic renal failure.

\section{Methods}

A retrospective study was conducted from January to August 2017 at Tabba Kidney Institute, Karachi. A total of 255 patients on hemodialysis were included in the study by using convenient sampling technique. All the relevant data such as gender, age, duration of hemodialysis and presence of hepatitis B and C were recorded. Data were analyzed using Statistical Package for Social Sciences, version 21 (IBM Corp., Armonk, NY) while binary logistic regression was applied to develop a risk assessment model for the study outcomes.

\section{Results}

The study results showed that 134 (52.5\%) patients were on hemodialysis for five years or more, 173 (67.8\%) of them suffered from hepatitis B while 124 (48.6\%) of them suffered from hepatitis C. The study results further revealed that after controlling for the effects of age and gender, the duration of hemodialysis was significantly associated with both hepatitis B (AOR 1.917, 95\% CI 1.111-3.306, $\mathrm{p}=0.019$ ) and hepatitis C (AOR $2.323,95 \%$ CI 1.395-3.870, $\mathrm{p}=0.001$ ) among the patients studied.

\section{Conclusion}

The study concluded that longer duration of hemodialysis in patients with chronic renal failure was significantly associated with both hepatitis B and hepatitis C infections in the study population. A myriad of patient and environmental factors can contribute to this finding in patients with chronic renal insufficiency. Therefore, periodic monitoring of liver function tests and routine surveillance for viral hepatitis can help establish an early diagnosis of infection, potentially improving patient outcomes improving patient outcome.

Review began 09/14/2020 Review ended 10/08/2020 Published 10/12/2020

\section{(c) Copyright 2020}

Elahi et al. This is an open access article distributed under the terms of the Creative Commons Attribution License CC-BY 4.0., which permits unrestricted use, distribution, and reproduction in any medium, provided the original author and source are credited.
Categories: Nephrology

Keywords: hepatitis b, hepatitis c, hemodialysis, chronic renal failure, chronic kidney disease

\section{Introduction}

Viral hepatitis is a leading cause of health loss as well as deaths worldwide. Its burden and relative rank had been raised to seventh position in 2013 compared with 10th to 12th rank in 1990 [1]. The Global Health Sector Strategy (GHSS) on viral hepatitis and World Health Assembly in 2016, set a goal for elimination of hepatitis as a public health threat by 2030 so that the death rate will be reduced which is accountable due to hepatitis B virus (HBV) and hepatitis C virus (HCV) infections [2]. Furthermore, after the introduction of new and improved antiviral therapy and direct-acting antiviral (DAA) therapy for chronic HCV, its efficacy and uptake; there is a great opportunity to improve public health by reducing liver-related mortality [3].

Chronic renal failure (CRF) patient's treatment with maintenance invasive hemodialysis (HD) therapy, badly affects the immune system of the patients. The procedure itself reduces the cellular immunity of HD patients. Several changes occur in normal physiology of these patients such as functions of leukocytes, neutrophils and monocytes and as well as natural killer cells become affected [4]. Additionally, HD therapy also leads to defective proliferation and down-regulation of the phosphorylation pathways of T-lymphocytes [5]. Due to weak immune system, the patients receiving hemodialysis (HD) therapy are prone to acquire blood-borne viral infections like hepatitis B virus (HBV), hepatitis C virus (HCV) and human immunodeficiency virus (HIV) as compared to those with the strong immune system [6]. These viral infections alone or with co-infections may induce hepatic inflammation, leading to hepatic cirrhosis and 
eventually, hepatocellular carcinoma [7]. The prevalence of HBV infection in dialysis centers varies according to the country. It ranges between $1.2 \%$ and $6.6 \%$ in developed countries and $1.3 \%$ to $14.6 \%$ in developing countries [8]. Similarly, the percentage of HCV infection ranges from $4.7 \%$ to $41.9 \%$ in developing countries and $1.4 \%$ to $28.3 \%$ in developed countries [9].

Factors associated with viral hepatitis in HD patients include a high incidence of HBV and HCV infections in the general population, lack of standard prevention measures and improper or no vaccination, no screening of patients for HBV and HCV before HD therapy, no proper arrangement for disinfecting dialysis machines as well as the spread of infection from one patient to another, recurrent blood transfusions, and long-term exposure to infectious agents through the extracorporeal circulation [10]. HCV and HBV infections are reported usually due to patient to patient transmission within HD units [11].

This is very important for health professionals and policymakers to give importance to frequency of bloodborne viruses in HD units and to identify the major risk factors so that they can operate the system more efficiently. This will ultimately decrease the rate of viral infections; lower the rates of morbidity and mortality. The goal of the present study was to investigate the prevalence of viral infections HBV and HCV, in patients with the end-stage renal failure on hemodialysis in our setting.

\section{Materials And Methods}

This was a retrospective study conducted from January to August 2017 at Tabba Kidney Institute, Karachi, Pakistan. Keeping the percentage frequency of the study outcome as $50 \%$ for the most liberal estimate, with 95\% confidence level and 6.5\% precision, the minimum sample size was calculated to be 228 participants. Against the calculated sample size, a total of 255 patients were included in the study by using the convenient sampling technique. Patients aged more than 18 years who were on hemodialysis for more than six months were included in the study. Patients with multi-organ failure, with illnesses other than kidney disease, and those who refused to give informed consent were excluded from the study. Later, participants were explained about the research and informed consent was obtained.

All the relevant data such as gender, age, duration of hemodialysis, and the presence of hepatitis B and C were recorded. The patients were divided into two groups based on the duration of hemodialysis: (i) less than five years duration and (ii) five years or greater duration.

Data were analyzed on the Statistical Package for Social Sciences (SPSS) version 21 (IBM Corp., Armonk, NY). Descriptive analysis was performed by generating means and standard deviations for continuous variables and frequencies and percentages for categorical variables. Binary logistic regression was applied to develop a risk assessment model for the study outcomes while keeping the significance level at 0.05 .

\section{Results}

A total of 255 patients were included in the study. The mean age of the study participants was $49.43 \pm 14.61$ years. 134 (52.5\%) of the patients were above 49 years of age. Almost one-half were female, 129 (50.6\%). The mean duration of the hemodialysis was $6.50 \pm 5.33$ years. 134 (52.5\%) of the patients were on hemodialysis for more than five years. 173 (67.8\%) of them suffered from hepatitis B while 124 (48.6\%) of them suffered from hepatitis C (Table 1$)$. 


\section{Cureus}

\section{Variables $(n=255)$}

Age (Years)

Age Groups

Up to 49 Years

50 or Above Years

Gender

Male

Female

Hemodialysis Duration (Years)

Hemodialysis Duration Groups

Less than 5 Years

5 or More Years

Hepatitis B

Yes

No

Hepatitis C

Yes

No
Mean \pm SD/frequency $(\%)$

$49.43 \pm 14.61$

134 (52.5)

121 (47.5)

126 (49.4)

$129(50.6)$

$6.50 \pm 5.33$

$121(47.5)$

$134(52.5)$

$173(67.8)$

82 (32.2)

$124(48.6)$

$131(51.4)$

\section{TABLE 1: Demographic and clinical characteristics of patients}

The study results further showed that after controlling for the effects of age and gender, the duration of hemodialysis was significantly associated with both hepatitis B (AOR1.917, 95\% CI 1.111-3.306, p=0.019) and hepatitis C (AOR 2.323, 95\% CI 1.395-3.870, $\mathrm{p}=0.001$ ) where patients who were on hemodialysis for five years or more had significantly higher odds of having hepatitis B and hepatitis C than those who were on hemodialysis for less than five years (Table 2).

\begin{tabular}{|c|c|c|c|c|c|}
\hline \multirow{2}{*}{ Varıables $(n=255)$} & & \multirow{2}{*}{ Adjusted Odds Ratio } & \multicolumn{2}{|l|}{$95 \% \mathrm{Cl}$} & \multirow{2}{*}{ p-value } \\
\hline & & & Lower & Upper & \\
\hline \multicolumn{6}{|c|}{ Hepatitis B } \\
\hline Hemodialysis Duration (Years) & 5 or More & 1.917 & 1.111 & 3.306 & 0.019 \\
\hline \multicolumn{6}{|c|}{ Hepatitis C } \\
\hline Hemodialysis Duration (Years) & 5 or More & 2.323 & 1.395 & 3.87 & 0.001 \\
\hline
\end{tabular}

TABLE 2: Adjusted odds ratios of association between hemodialysis duration and hepatitis $B$ and C

\section{Discussion}

Chronic kidney disease (CKD) is linked with kidney damage and decrease glomerular filtration rate (GFR) for almost three months. CKD badly affects the quality of life, enhance the health care expenditures, rate of morbidity and mortality, and lead to premature death [12]. Long-standing CKD results in end-stage kidney disease (ESKD). In ESKD, uremic waste products are retained in the body and require renal replacement therapies, such as HD and kidney transplantation [13]. HD therapy is utilized not only in those patients who 
have an acute illness and need short-term dialysis for days to weeks so that kidney will resume its function, and also on those patients who are critically ill with advanced CKD and/or ESKD and necessitate long-term or permanent renal replacement therapy [14].

It has been observed that viral infections are common in chronic hemodialysis (CHD) patients, particularly the viral hepatitis B and C, and HIV infections. Its prevalence differs from country to country and between HD centers.

Present study was conducted in Karachi, Pakistan; in this study, we found that the prevalence of HBV was high in HD patients with a duration more than five years, and that there is a significant positive association between HBV positivity and duration of dialysis. Our results are distressingly high as compare to previously mentioned results from other previous studies conducted in Pakistan. A study conducted in Karachi, Pakistan showed $10.2 \%$ of HD patients [15], another study conducted in Islamabad, Pakistan depicted $12.5 \%$ of HD patients [16], one study from Quetta showed 16.1\% of HD patients found to be positive for HBV [17], these results were in contrast to $6 \%$ HBV positivity in general population of Pakistan [18]. All these studies also showed that the duration of dialysis was significantly correlated with positivity of HBV in HD patients similar to our findings. WHO's consideration for countries to be high endemic region of HBV is almost 5\% carrier rate [19]. However, the prevalence of hepatitis B in Pakistan is around $4 \%$ to $6 \%$ in general population [20]. Because there is large pool of delta positive cases in some regions of Sind, Punjab and Baluchistan [20-22] and also a low EPI coverage of hepatitis B vaccine, the chances for the spread of viral infection are high [23]. Hence, regarding our findings, we can postulate that this high burden of HBV in HD patients is probably due to already high burden of HBV in general population and particularly immunecompromised chronic kidney disease patients too. The other important factor is the contamination of dialysis machines after reuse and lack of following standard operating procedures regarding the cleanliness of equipment.

The prevalence of HCV is $48.6 \%$ in HD patients with a duration of more than five years in the present study. The positivity of HCV in HD was significantly associated with the duration of dialysis. Our results are comparable with other previous studies conducted worldwide and in Pakistan. A study conducted in Karachi showed that the HCV was positive in $20 \%$ of HD therapy patients [13]. Similarly, another study from Quetta Pakistan showed that $43.2 \%$ of HD patients were positive for HCV [15]. These results are comparable with our findings. A multicenter study conducted in Saudi Arabia involving 22 HD centers and including 1147 patients found $68 \%$ of HD were positive for HCV ranges from $14.5 \%$ to $94.7 \%$ [24]. This was the highest prevalence observed in the world. They also depicted that this was significantly associated with duration of dialysis. The most important risk factor they describe was a lack of adherence to standard universal infection precautions.

The viral hepatitis infections are major health issues in both developed and developing countries because of being the leading cause of health loss and deaths in patients receiving HD treatment. The progressive risk to develop either cirrhosis or hepatocellular carcinoma after viral hepatitis is very high in HD patients. This is high time for healthcare professionals and policymakers to take urgent actions against this endemic condition. HD centers must adopt internationally accepted immunization standards and infection control policies, in order to minimize the burden of HBV and HCV in patients already burdened by their advanced kidney disease.

We view our study with a few limitations. First, we utilized convenient sampling for data collection, which introduces bias by multiple factors that cannot be controlled. Confounding factors that could not be controlled in our study include lack of information regarding HBsAb status and history of vaccination before the diagnosis of chronic hepatitis B. Centre for Disease Control and Prevention (CDC) recommends hepatitis $\mathrm{B}$ and $\mathrm{C}$ screening at least once in a lifetime for all adults aged 18 years and older, except in settings where the prevalence of HBV and HCV infection is less than 0.1\% [25]. Unfortunately, in Pakistan, no such screening is performed routinely. In fact, in certain rural and urban areas, screening for blood donors is also not performed and syringes are reused that ultimately leads to a high disease burden.

\section{Conclusions}

Hemodialysis is among the major factors that cause viral infections including HBV, HCV, or HIV, this is because patients on hemodialysis can catch an infection through blood transfusion, dialysis machines, instruments, or other contaminated equipment. There is an immense need to control the spread of viral infections through several means like increased public awareness, patients screening before dialysis, vaccinations, and health education programs for both health care providers and patients.

\section{Additional Information \\ Disclosures}

Human subjects: Consent was obtained by all participants in this study. Not needed issued approval Not needed. IRB approval was not needed as this was a retrospective study. Animal subjects: All authors have confirmed that this study did not involve animal subjects or tissue. Conflicts of interest: In compliance 
with the ICMJE uniform disclosure form, all authors declare the following: Payment/services info: All authors have declared that no financial support was received from any organization for the submitted work. Financial relationships: All authors have declared that they have no financial relationships at present or within the previous three years with any organizations that might have an interest in the submitted work. Other relationships: All authors have declared that there are no other relationships or activities that could appear to have influenced the submitted work.

\section{References}

1. Stanaway JD, Flaxman AD, Naghavi M, et al.: The global burden of viral hepatitis from 1990 to 2013 : findings from the Global Burden of Disease Study 2013. Lancet. 2016, 388:1081-1088. 10.1016/S01406736(16)30579-7

2. Organization WH. Global health sector strategy on viral hepatitis 2016-2021. Towards ending viral hepatitis. World Health Organization. (2016).

3. Dore GJ, Ward J, Thursz M: Hepatitis C disease burden and strategies to manage the burden (Guest Editors Mark Thursz, Gregory Dore and John Ward). J Viral Hepatitis. 2014. 21:1-4. 10.1111/jvh.12253

4. Kato S, Chmielewski M, Honda H, et al.: Aspects of immune dysfunction in end-stage renal disease . Clin J Am Soc Nephrol. 2008, 3:1526-1533. 10.2215/CJN.00950208

5. Eleftheriadis T, Kartsios C, Yiannaki E, et al.: Chronic inflammation and T cell zeta-chain downregulation in hemodialysis patients. Am J Nephrol. 2008, 28:152-157. 10.1159/000110020

6. Ali N, Hussain W, Hayat A, et al.: Prevalence and risk factors of hepatitis B and C viruses among haemodialysis patients: a multicentric study. Eur J Gastroenterol Hepatol. 2019, 31:29-33. 10.1097/MEG.0000000000001220

7. Yoon JS, Lee HY, Chung SW, et al.: Prognostic impact of concurrent non-alcoholic fatty liver disease in patients with chronic hepatitis B-related hepatocellular carcinoma. J Gastroenterol Hepatol. 2020, 10.1111/jgh.15026

8. Johnson DW, Dent H, Yao Q, et al.: Frequencies of hepatitis B and C infections among haemodialysis and peritoneal dialysis patients in Asia-Pacific countries: analysis of registry data. Nephrol Dialysis Transplantation. 2009, 24:1598-603. 10.1093/ndt/gfn684

9. Fabrizi F, Messa P: The epidemiology of HCV infection in patients with advanced CKD/ESRD: A global perspective. Semin Dialysis. 2019, 32:93-98. 10.1111/sdi.12757

10. Roushan MR, Farokhtabar S, Bayani M, Siadati S: Epidemiological aspects of hepatitis B and C and human immunodeficiency viruses among hemodialysis patients in Mazandaran Province, Iran. Nephro-Urol Monthly. 2016, 8:e37878. 10.5812/numonthly.37878

11. Ozer A, Yakupogullari Y, Beytur A, Beytur L, Koroglu M: Risk factors of hepatitis B virus infection in Turkey: a population-based, case-control study: risk Factors for HBV Infection. Hepatitis Monthly. 2011, 11:263.

12. Beauger D, Gentile S, Jacquelinet C, Dussol B, Briancon S: Comparison of two national quality of life surveys for patients with end stage renal disease between 2005-2007 and 2011: indicators slightly decreased. Nephrol Ther. 2014, 11:88-96. 10.1016/j.nephro.2014.10.003

13. Foster MC, Inker LA, Hsu C-y, et al.: Filtration markers as predictors of ESRD and mortality in Southwestern American Indians with type 2 diabetes. Am J Kidney Dis. 2015, 66:75-83. 10.1053/i.ajkd.2015.01.013

14. Mutsaers HA, Stribos EG, Glorieux G, Vanholder R, Olinga P: Chronic kidney disease and fibrosis: the role of uremic retention solutes. Front Med. 2015, 2:60. 10.3389/fmed.2015.00060

15. Idrees MK, Batool S, Ahmed E: Hepatitis B virus among maintenance haemodialysis patients: a report from Karachi, Pakistan. J Pakistan Med Assoc. 2011, 61:1210-1214.

16. Bosan A, Qureshi H, Bile KM, Ahmad I, Hafiz R: A review of hepatitis viral infections in Pakistan . J Pakistan Med Assoc. 2010, 60:1045-1058.

17. Lodhi A, Sajjad A, Mehmood K, et al.: Profile and predictors of hepatitis and HIV infection in patients on hemodialysis of Quetta, Pakistan. Drug Discov Ther. 2019, 13:274-279. 10.5582/ddt.2019.01044

18. ul Haq N, Hassali MA, Shafie AA, Saleem F, Farooqui M, Aljadhey H: A cross sectional assessment of knowledge, attitude and practice towards Hepatitis B among healthy population of Quetta, Pakistan. BMC Public Health. 2012, 12:692. 10.1186/1471-2458-12-692

19. Organization WH: Treatment and care for HIV-positive injecting drug users: Module 12-Continuing medical education. 2007 https://apps.who.int/iris/handle/10665/206037.

20. Uddin G, Shoeb D, Solaiman S, et al.: Prevalence of chronic viral hepatitis in people of south Asian ethnicity living in England: the prevalence cannot necessarily be predicted from the prevalence in the country of origin. J Viral Hepatitis. 2010, 17:327-335. 10.1111/j.1365-2893.2009.01240.x

21. Riaz A, Zuberi SJ, Qureshi H, Alam SE: Delta hepatitis in Pakistan. Tropical Doctor. 2005, 35:121. 10.1258/0049475054037129

22. Mumtaz K, Hamid SS, Adil S, et al.: Epidemiology and clinical pattern of hepatitis delta virus infection in Pakistan. J Gastroenterol Hepatol. 2005, 20:1503-1507. 10.1111/j.1440-1746.2005.03857.x

23. Studies NIoP, Inc MI. Pakistan demographic and health survey 2006-07. National Institute of Population Studies and Macro International Inc Islamabad 2008. https://dhsprogram.com/pubs/pdf/FR200/FR200.pdf.

24. Huraib S, al-Rashed R, Aldrees A, Aljefry M, Arif M, al-Faleh FA: High prevalence of and risk factors for hepatitis C in haemodialysis patients in Saudi Arabia: a need for new dialysis strategies. Nephrol Dialysis Transplantation. 1995, 10:470-474. 10.1093/ndt/10.4.470

25. Schillie S, Wester C, Osborne M, Wesolowski L, Ryerson AB: CDC recommendations for hepatitis C screening among adults-United States. 2020. MMWR Recomm Rep 2020, 69:(No. RR-2).. https://www.cdc.gov/hepatitis/hcv/pdfs/HepCScreening2020RecsSummary.pdf 